J. Clin. Chem. Clin. Biochem.

Vol. 25, 1987, pp. $151-160$

(C) 1987 Walter de Gruyter \& Co.

Berlin - New York

\title{
Pathobiochemical Significance of Granulocyte Elastase Complexed with Proteinase Inhibitors: Effect on Glycosaminoglycan Metabolism in Cultured Synovial Cells
}

\author{
By $K$. Kleesiek, E. van de Leur, R. Reinards and H. Greiling \\ Department of Clinical Chemistry and Pathobiochemistry, \\ Aachen University of Technology, Aachen, Federal Republic of Germany
}

(Received October 16/December 4, 1986)

Summary: Interactions between elastase inhibitor complexes and synovial cells are of special interest, since, in chronic joint diseases, granulocytes release large amounts of elastase into the synovial fluid and connective tissue, where the proteinase is bound to $\alpha_{1}$-proteinase inhibitor and $\alpha_{2}$-macroglobulin. To study the effect of elastase- $\alpha_{2}$-macroglobulin and elastase- $\alpha_{1}$-proteinase inhibitor complexes on the glycosaminoglycan metabolism of cultured synovial cells, we determined the distribution of $\left[{ }^{3} \mathrm{H}\right]$ glucosamine-labelled hyaluronate, which represents the main synthesized glycosaminoglycan, and of ${ }^{35} \mathrm{SO}_{4}^{2-}-$-labelled chondroitin sulphate into the intracellular, pericellular and extracellular compartments of the cell culture. Exposure of the synovial cells to elastase- $\alpha_{2}$-macroglobulin complexes leads to an enhanced synthesis and secretion of hyaluronate and chondroitin sulphate, and also induces a rise of the fibronectin concentration in the medium. Analogous but less pronounced effects are observed in the presence of elastase- $\alpha_{1}$-proteinase inhibitor complexes. Native uncomplexed elastase, however, causes no significant changes in hyaluronate metabolism. An increase of prostaglandin $\mathrm{E}_{2}$ in the culture medium during incubation with elastase inhibitor complexes occurs in parallel to the stimulatory effect on glycosaminoglycan metabolism. Our results demonstrate that elastase, whose enzymic activity is inactivated by the formation of complexes with $\alpha_{1}$-proteinase inhibitor or $\alpha_{2}$-macroglobulin, nevertheless acts as an inflammatory mediator, which in vitro induces metabolic changes closely resembling the in vivo findings in inflammatory joint diseases.

\section{Introduction}

In inflammatory joint diseases a variety of proteolytic enzymes are responsible for the degradation of matrix components of articular cartilage $(1-4)$. Proteinases shown to be involved in connective tissue breakdown are the neutral proteináses, elastase, cathepsin $G$ and collagenase, which are released from granulocytes mainly during phagocytosis, after cell death, and exposure to fluid factors like complement and interleukin I (5-8). In particular, elastase is released in large amounts and is therefore of special pathogenic and diagnostic importance (9). After release of elastase into the extracellular space, this cationic serine pro- teinase becomes bound to proteinase inhibitors; in serum about $90 \%$ is bound to $\alpha_{1}$-proteinase inhibitor and about $10 \%$ to $\alpha_{2}$-macroglobulin (10). Elastase$\alpha_{1}$-proteinase inhibitor complexes are enzymatically inactive (11), whereas $\alpha_{2}$-macroglobulin forms complexes with elastase, which are still enzymatically active towards small protein substrates (molecular weight: < 10000) (12).

Elastase inhibitor complexes are phagocytosed by macrophages at the site of inflammation and are removed from the blood circulation by tissue macrophages in liver and spleen (13). It has been shown that fixed macrophages are activated by endocytosis 
of proteinase- $\alpha_{2}$-macroglobulin complexes to produce and secrete neutral proteinases (14) and probably prostaglandins. Thus, the disposal of elastase- $\alpha_{2}$-macroglobulin complexes seems to be a way of amplifying inflammation and might be involved in the stimulation of hepatic acute phase protein synthesis (15).

High levels of elastase complexed with proteinase inhibitors are detectable in synovial fluids of patients with chronic inflammatory joint diseases $(16-18)$. The concentration of elastase- $\alpha_{1}$-proteinase inhibitor complexes, which are found in inflammatory synovial fluids, is often extremely enhanced (up to $100 \mathrm{mg} / \mathrm{l}$ ), compared with those in non-inflammatory synovial fluids and normal plasma $(50-150 \mu \mathrm{g} / \mathrm{l})$.

Detailed studies on the influence of elastase-proteinase inhibitor complexes on the metabolism of surrounding connective tissue cells in the joint cavity are still lacking. In the present work we used synovial fibroblast cultures as a defined model to investigate the influence. of elastase-proteinase inhibitor complexes on the metabolism of these connective tissue cells in the synovial system.

\section{Materials and Methods}

\section{Chemicals}

Human granulocyte elastase, $\alpha_{1}$-proteinase inhibitor and $\alpha_{2}$ macroglobulin are research products of the Biochemical Research Department of E. Merck (Darmstadt, FRG). Eagle's minimum essential medium (MEM), Earle's salt and foetal calf serum were obtained from Flow Laboratories (Bonn, FRG), platelet-derived-growth-factor (PDGF), type I, from Collaborative Research Inc. (Waltham, Mass., USA), and the radiochemicals $\left[{ }^{3} \mathrm{H}\right]$ glucosamine (specific activity: $27.6 \mathrm{MBq} / \mathrm{mmol}$ ) and ${ }^{35} \mathrm{SO}_{4}^{2-}$ (specific activity: $1.2 \mathrm{GBq} / \mathrm{mmol}$ ) from New England Nuclear (NEN)-Chemicals (Dreieich, FRG). Hyaluronate lyase, chondroitin AC lyase and chondroitin ABC lyase were purchased from Seikagaku (Kogyo, Japan). Sephacryl S-400 was obtained from Pharmacia Fine Chemicals (Uppsala, Sweden).

\section{Cell culture}

Synovial cells were grown from tissue pieces excised from the knee-joint capsule of a 30-year-old man during meniscectomy. Cell cultivation was performed by a method described elsewhere (19). The cells were detached from the synovial membrane by incubation in $2.5 \mathrm{~g} / \mathrm{l}$ trypsin in Earle's balanced salt solution for $15 \mathrm{~min}$ at room temperature on a magnetic stirrer. After filtration (gauze filter) and centrifugation of the filtrate $(400 \mathrm{~g}$, $20 \mathrm{~min}$ ) the pellet was suspended in culture medium (see below) enriched with foetal calf serum to give a volume fraction of 0.2 , and about $0.6 \times 10^{6}$ cells in $20 \mathrm{ml}$ medium were placed into each $25 \mathrm{ml}$ Falcon culture flask (Nunc, Wiesbaden, FRG).

\section{Culture conditions}

Primary cultures of synovial fibroblasts were maintained at $37^{\circ} \mathrm{C}$ in Eagle's minimum essential medium, modified with
Earle's salt and supplemented with penicillin (100 IU $/ \mathrm{ml})$, streptomycin $(100 \mathrm{mg} / \mathrm{l})$, amphotericin $\mathrm{B}(2.5 \mathrm{~g} / \mathrm{l})$ and foetal calf serum: volume fraction 0.2 . A humidified atmosphere of $5 \%$ $\mathrm{CO}_{2}$ in air was used. Medium changes were performed every $48 \mathrm{~h}$. After the third to fourth subculturing, $0.6 \times 10^{6}$ cells were incubated in $25 \mathrm{~cm}^{2}$ culture flasks (Nunc) until confluent monolayers with densities of about $0.6 \times 10^{5} \mathrm{cells} / \mathrm{cm}^{2}$ were achieved. Subsequently, the cells were incubated for $24 \mathrm{~h}$ in $4.5 \mathrm{ml}$ serum-depleted minimum essential medium, containing platelet derived growth factor $(0.64 \mathrm{U} / \mathrm{ml})$, antibiotics and the radioactive precursors [ [ $[3]$ glucosamine and ${ }^{35} \mathrm{SO}_{4}^{2-}$ in final concentrations of $56 \mathrm{kBq} / 1$ and $0.56 \mathrm{MBq} / \mathrm{l}$, respectively. During the incubation time of $24 \mathrm{~h}$ the cell number of the monolayers remained constant.

The effect of elastase, elastase- $\alpha_{1}$-proteinase inhibitor complexes, elastase- $\alpha_{2}$-macroglobulin complexes, $\alpha_{1}$-proteinase inhibitor and $\alpha_{2}$-macroglobulin on the synovial cell metabolism was studied using the following agent concentrations in the culture medium: elastase $(0.22,2.24$ and $22.4 \mathrm{nmol} / \mathrm{l})$, elastase$\alpha_{1}$-proteinase inhibitor complexes (25.1 and $\left.251 \mathrm{nmol} / \mathrm{l}\right)$, elastase- $\alpha_{2}$-macroglobulin complexes (11.5 and $\left.115 \mathrm{nmol} / \mathrm{l}\right), \alpha_{1}-$ proteinase inhibitor $(1574 \mathrm{nmol} / \mathrm{l}), \alpha_{2}$-macroglobulin (125 $\mathrm{nmol} / \mathrm{l})$, assuming relative molecular masses of 28000,53000 and 725000 for elastase, $\alpha_{1}$-proteinase inhibitor and $\alpha_{2}$-macroglobulin, respectively.

All experiments in the presence or absence of elastase proteinase inhibitor complexes were performed in 14-fold parallel trials, using 5 cultures for the isolation of radioactive glycosaminoglycans and 3 cultures each for counting the cells, determination of total protein content and concentration of prostaglandin/ fibronectin.

\section{Isolation of radioactive glycosaminoglycans}

The radioactive peptidoglycosaminoglycans were isolated from topographically distinct pools of the cell culture, as described elsewhere (19). Firstly, the medium, which represents the extracellular compartment, was removed and the cell layer rinsed 5 times with $5 \mathrm{ml}$ phosphate-buffered saline. After treatment with $3 \mathrm{ml}$ trypsin solution (see above) the dispersed cells were centrifuged $\left(400 \mathrm{~g}, 10 \mathrm{~min}, 4^{\circ} \mathrm{C}\right)$, the supernate being the pericellular compartment (tryptic fraction). After washing 3 times with $5 \mathrm{ml}$ phosphate-buffered saline the pellet was processed as the intracellular compartment.

The material of the different pools was then subjected to proteolytic digestion with pronase from Streptomyces griseus in phosphate-buffered saline ( $\mathrm{pH} 7.5,37^{\circ} \mathrm{C}, 24 \mathrm{~h}$ ) in a final concentration of $5 \mathrm{~g} / \mathrm{l}$ (cell pellet) or $1.25 \mathrm{~g} / \mathrm{l}$ (medium, tryptic fraction). Subsequently, the 3 trial compartments were treated identically. After addition of carrier glycosaminoglycans (hyaluronic acid : chondroitin sulphate $=2: 1$ ) and precipitation with a 4fold volume of ethanol saturated with sodium acetate, repeated proteolysis of the precipitate with papain (specific activity: 30 $\mathrm{U} / \mathrm{mg}, 15 \mathrm{U}$ per test, $\mathrm{pH} 4.5,56^{\circ} \mathrm{C}, 24 \mathrm{~h}$ ) was carried out. Precipitation of the protein with trichloroacetic acid (final concentration $50 \mathrm{~g} / \mathrm{l}$ ) and centrifugation were followed by neutralization and exhaustive dialysis of the supernate against water and precipitation of the peptidoglycosaminoglycans with cetylpyridinium chloride (final concentration $10 \mathrm{~g} / 1$ in 0.04 $\mathrm{mol} / \mathrm{l} \mathrm{NaCl}$ ). After standing overnight at room temperature, the sediment was obtained by centrifugation at $7500 \mathrm{~g}$ for 20 $\mathrm{min}$. The precipitated cetylpyridinium chloride-glycosaminogly= can complex was solubilized in $2 \mathrm{~mol} / 1 \mathrm{NaCl}$ and ethanol (volume fraction 0.15 in water), and the glycosaminoglycans were again precipitated with 4 volumes of ethanol.

Radioactivity was measured in a liquid scintillation counter (Rackbeta 1217, LKB, Bromma, Sweden). Results were expressed as radioactivity of ${ }^{3} \mathrm{H}=$ or ${ }^{35} \mathrm{SO}_{4}^{2-}$-labelled glycosaminoglycans per $\mathrm{mg}$ protein. 
Determination of hyaluronate and chondroitin sulphate

For analysis of hyaluronate and chondroitin sulphate the purified precipitate containing the total glycosaminoglycans was degraded with hyaluronate lyase, chondroitin $A C$ lyase and chondroitin $A B C$ lyase, as described previously $(20,21)$. Radioactivity was determined in precipitate and supernate.

Preparation of elastase- $\alpha_{1}$-proteinase inhibitor complexes

Granulocyte elastase $(1.5 \mathrm{mg} ; 0.054 \mu \mathrm{mol})$ was incubated at $37^{\circ} \mathrm{C}$ with $1.5 \mathrm{mg}(0.028 \mu \mathrm{mol}) \alpha_{1}$-proteinase inhibitor in the

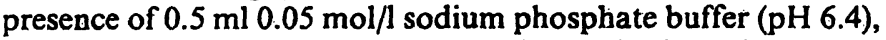
containing $0.5 \mathrm{~mol} / 1 \mathrm{NaCl}$. After $3 \mathrm{~h}$ the incubation mixture was subjected to gel filtration on sephacryl S-400 (column $16 \times 70$ $\mathrm{mm})$ and the elastase- $\alpha_{1}$-proteinase inhibitor-containing fractions were pooled and concentrated to $5 \mathrm{ml}$ by ultrafiltration (Amicon PM-10). The concentration of complexed elastase was determined by an enzyme immunoassay (22). The incubation was performed in the presence of excess native elastase, since the difference between the relative molecular masses of unbound elastase and formed elastase-inhibitor complexes allows a complete separation of both in the subsequent gel filtration chromatography.

Preparation of elastase- $\alpha_{2}$-macroglobulin complexes

Elastase- $\alpha_{2}$-macroglobulin complexes were prepared by incubation of $1.5 \mathrm{mg}(0.054 \mu \mathrm{mol})$ granulocyte elastase with $15 \mathrm{mg}$ $\alpha_{2}$-macroglobulin $(0.021 \mu \mathrm{mol})$ in $0.5 \mathrm{ml} 0.05 \mathrm{~mol} / 1$ sodium phosphate buffer, $0.5 \mathrm{~mol} / 1 \mathrm{NaCl}\left(\mathrm{pH} \mathrm{6.4)}\right.$ for $3 \mathrm{~h}$ at $37^{\circ} \mathrm{C}$. Subsequent purification of the complexes was achieved by gel filtration on a Sephacryl S-400 column $(16 \times 70 \mathrm{~mm})$. Elastase$\alpha_{2}$-macroglobulin complex-containing fractions were pooled and concentrated to $5 \mathrm{ml}$.

\section{Other methods}

Protein content was measured according to Lowry et al. (23) with bovine serum albumin as a standard. Glucose (24) and lactate (25) were measured enzymatically using a centrifugal fast analyzer Cobas Bio (Hoffmann-La Roche, Basel, Switzerland). Fibronectin was determined by radial immunodiffusion (LCPartigen plates, Behring Werke, Marburg, FRG). Prostaglandin $\mathrm{E}_{2}$ was determined by radioimmunoassay using a commercial kit (NEN chemicals). Cell numbers were determined by examination of the hematoxylin-stained cell layer with a phasedifference inverse microscope using an ocular reticule micrometer.

\section{Statistical analysis}

The significance of differences was checked by a standard t-test for dependent samples (26). P values $<0.02$ werè considered significant.

\section{Results}

Effects of elastase-inhibitor complexes on the metabolism of cultured synovial cells

\section{Effect on hyaluronate}

Elastase-inhibitor complexes stimulate the incorporation of the radiolabelled precursors $\left[{ }^{3} \mathrm{H}\right]$ glucosamine and ${ }^{35} \mathrm{SO}_{4}^{2-}$ into the total glycosaminoglycans in a dose-dependent manner (fig. 1).

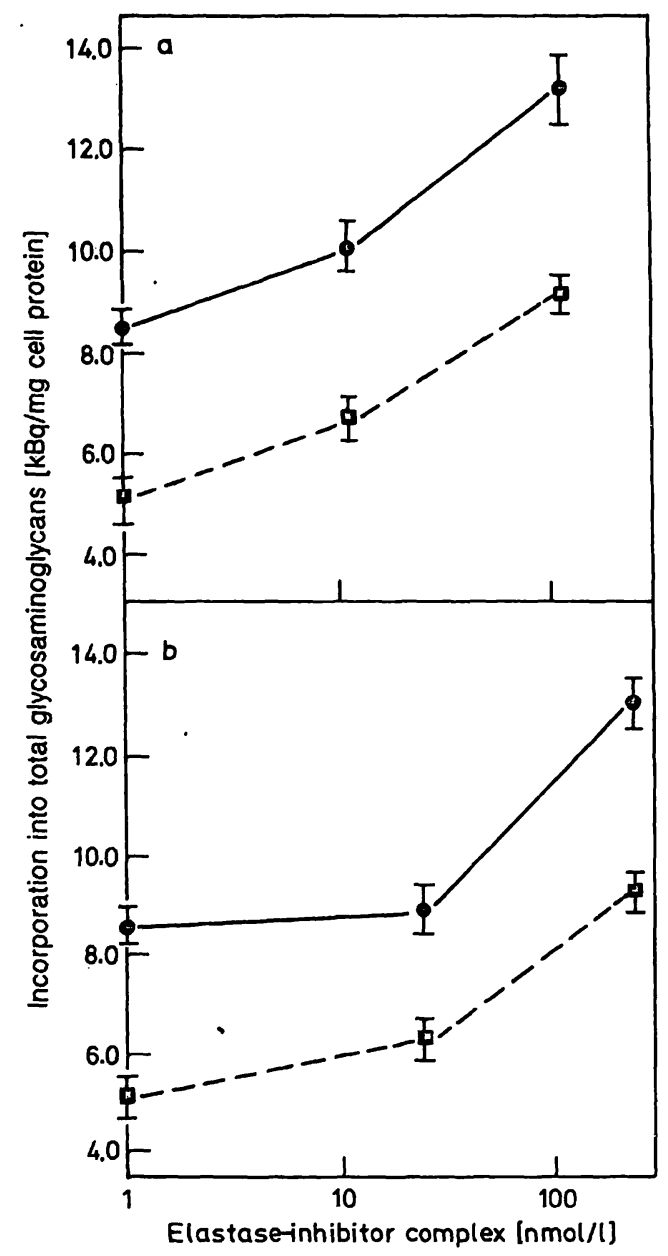

Fig. 1. Effect of

a) elastase- $\alpha_{2}$-macroglobulin complexes and

b) elastase- $\alpha_{1}$-proteinase inhibitor complexes

on the incorporation of $\left[{ }^{3} \mathrm{H}\right]$ glucosamine $(0-0)$ and ${ }^{35} \mathrm{SO}_{4}^{2-}(\square-\square)$ into total glycosaminoglycans of cultured synovial cells. Mean and standard deviation are given.

More detailed information about glycosaminoglycan metabolism is obtained from the measurement of the incorporation of radioactivity into both hyaluronate and chondroitin sulphate (fig. 2). Exposure of the cultured synovial fibroblasts to elastase- $\alpha_{2}$-macroglobulin complexes $(11.5,115 \mathrm{nmol} / \mathrm{l})$ dose-dependently stimulates the incorporation of $\left[{ }^{3} \mathrm{H}\right]$ glucosamine into total hyaluronate in a dose-dependent manner, especially in the extracellular pool (maximum increase of about $70 \%$ ), whereas at the same time the radioactive hyaluronate of the intracellular and the pericellular pool decreases by about $63 \%$ and $10 \%$, respectively.

The effects of elastase- $\alpha_{1}$-proteinase inhibitor complexes on the metabolism of hyaluronate are similar to those observed in the presence of elastase- $\alpha_{2}$-macroglobulin complexes (fig. 2). However, compared with elastase- $\alpha_{2}$-macroglobulin complexes, significant 

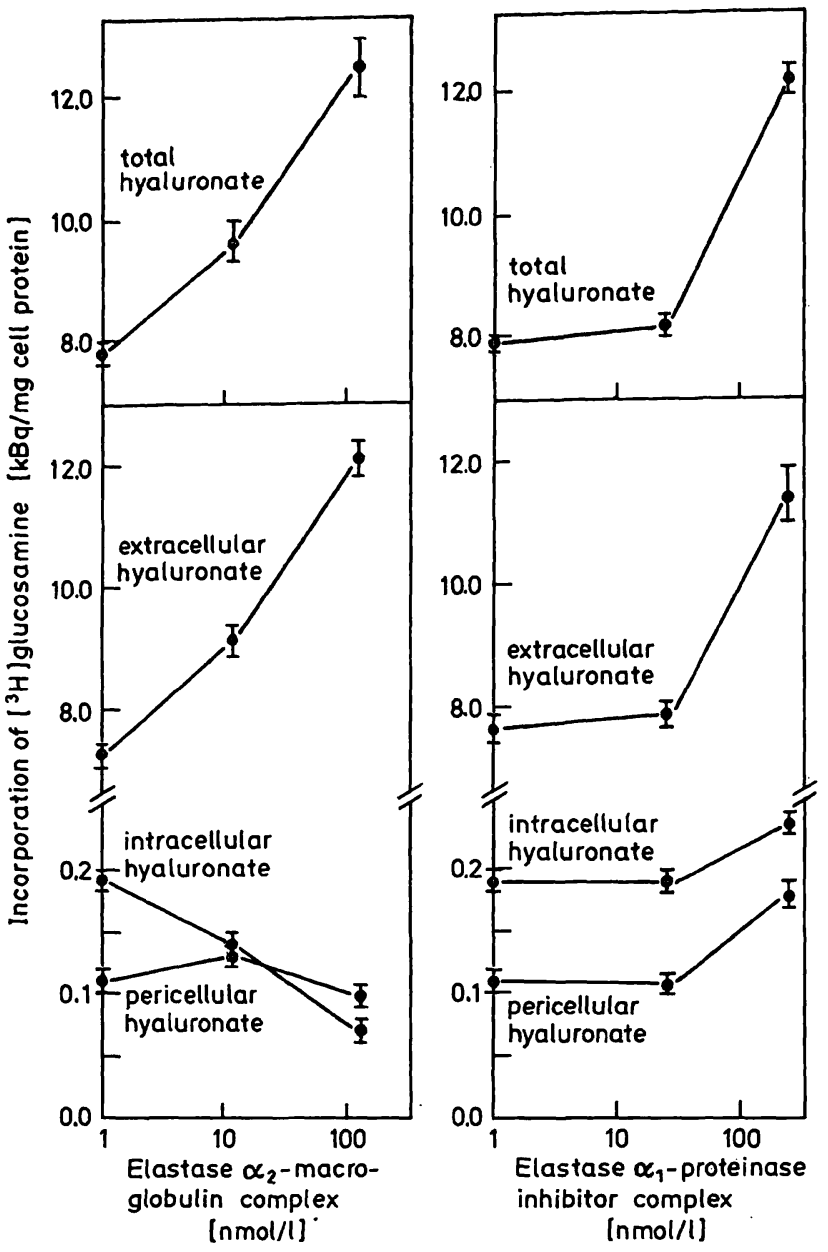

Fig. 2. Effect of elastase- $\alpha_{2}$-macroglobulin complexes and elastase- $\alpha_{1}$-proteinase inhibitor complexes on hyaluronate metabolism in cultured synovial fibroblasts. The radiolabelled hyaluronate was isolated from topographically distinct pools of the cell culture. Mean and standard deviation are given.

stimulatory effects of the elastase- $\alpha_{1}$-proteinase inhibitor complexes are observed only at higher molar concentrations (extracellular radioactive hyaluronate increases of about $49 \%$ at $251 \mathrm{nmol} / \mathrm{l}$ ).

\section{Effect on chondroitin sulphate}

As shown by enzymatic analysis, glycosaminoglycans secreted by cultured synovial fibroblasts are composed of about $90 \%$ hyaluronate. The remaining glycosaminoglycans consist of about $10 \%$ chondroitin sulphate, degraded by chondroitin AC lyase. Dermatan sulphate was detectable only in trace amounts.

In the presence of elastase- $\alpha_{2}$-macroglobulin complexes and elastase- $\alpha_{1}$-proteinase inhibitor complexes, the incorporation of ${ }^{35} \mathrm{SO}_{4}^{2-}$ into total chondroitin sulphate is enhanced (fig. 3). Especially the extracellular radiolabelled fraction is increased: about $72 \%$ and $110 \%$ during culturing with $115 \mathrm{nmol} / 1$ elastase- $\alpha_{2}-$
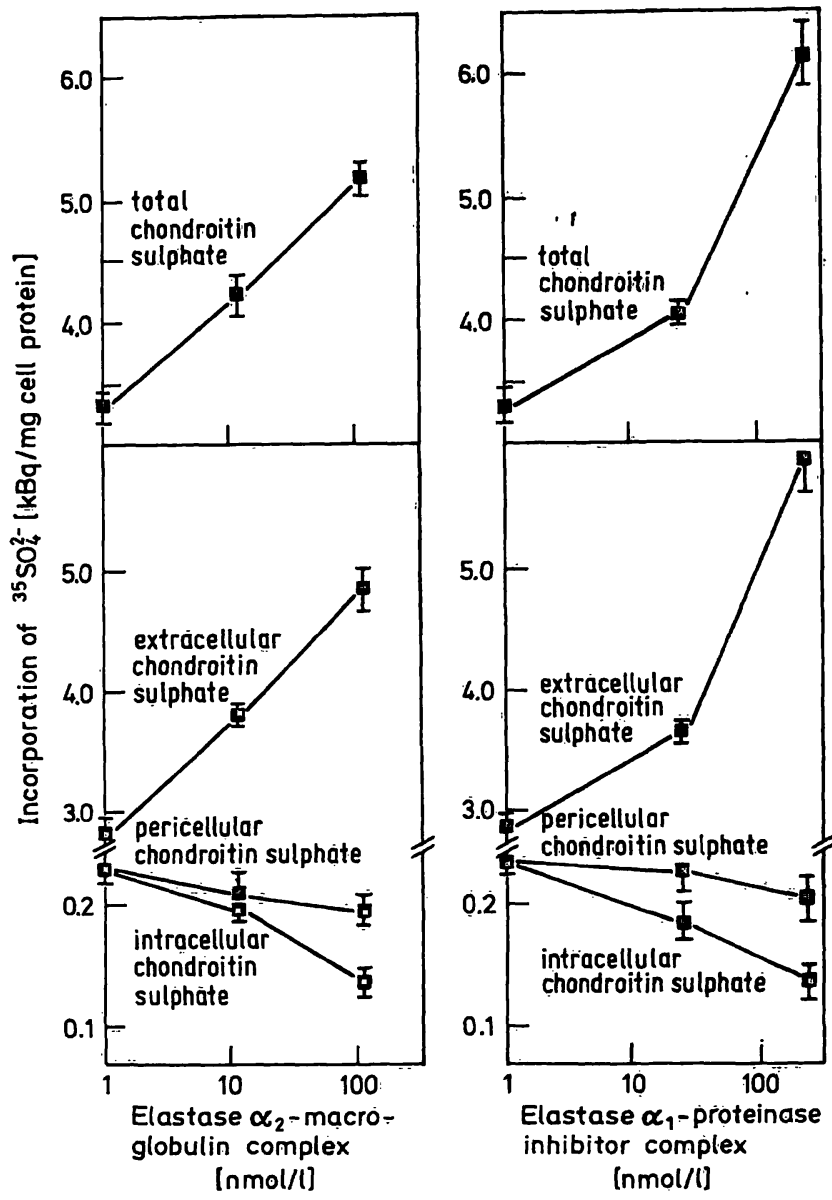

Fig. 3. Effect of elastase- $\alpha_{2}$-macroglobulin complexes and elastase- $\alpha_{1}$-proteinase inhibitor complexes on the metabolism of chondroitin sulphate in cultured synovial fibroblasts. The radioactive labelled chondroitin sulphate was isolated from topographically distinct pools of the cell culture. Mean and standard deviation are given.

macroglobulin and $251 \mathrm{nmol} / \mathrm{l}$ elastase- $\alpha_{1}$-proteinase inhibitor complexes, respectively. However, at the same time, the amount of radioactive chondroitin sulphate in the cells and the pericellular space is diminished by about $40 \%$ and $14 \%$, respectively.

\section{Effect on glycolysis}

Elastase-inhibitor complexes cause a significant increase of glucose uptake and lactic acid production. Glucose uptake increases from $3.42 \pm 0.15$ (standard deviation) $\mu \mathrm{mol} / 10^{6}$ cells in the absence of elastase$\alpha_{2}$-macroglobulin complexes to $3.99 \pm 0.15$ and 4.83 $\pm 0.08 \mu \mathrm{mol} / 10^{6}$ cells at complex concentrations of 11.5 and $115 \mathrm{nmol} / \mathrm{l}$, respectively. The lactic acid production rises from $6.91 \pm 0.23$ to $7.93 \pm 0.41$ and $9.96 \pm 0.30$. A similar but less pronounced effect on glucose uptake and lactic acid production is found in the presence of elastase- $\alpha_{1}$-proteinase inhibitor complexes at $251 \mathrm{nmol} / \mathrm{l}$. 


\section{Effect on prostaglandin $E_{2}$}

Addition of elastase- $\alpha_{2}$-macroglobulin complexes $(11.5,115 \mathrm{nmol} / \mathrm{l})$ and elastase- $\alpha_{1}$-proteinase inhibitor complexes $(25.1,251 \mathrm{nmol} / \mathrm{l})$ to the synovial fibroblast cultures leads to an increase of prostaglandin $E_{2}$ in the culture medium, which is more pronounced in the presence of elastase- $\alpha_{2}$-macroglobulin complexes (6-fold increase), whereas native elastase does not show a significant effect (fig. 4).

\section{Effect on fibronectin}

The fibronectin concentration in the culture medium is also affected by elastase inhibitor complexes. Elevated complex concentrations are able to evoke a strong stimulation of the fibronectin concentration in the culture medium: incubation with elastase- $\alpha_{2}-$ macroglobulin complexes $(115 \mathrm{nmol} / \mathrm{l})$ or with elastase- $\alpha_{1}$-proteinase inhibitor complexes $(251 \mathrm{nmol} / \mathrm{l})$ leads to a 12-fold or 6-fold increase of fibronectin concentration, respectively (fig. 5). However, no stimulatory effect was observed at lower concentrations of the elastase- $\alpha_{2}$-macroglobulin and elastase$\alpha_{1}$-proteinase inhibitor complexes (11.5 and 25.1 nmol/1, respectively).

Culturing synovial cells in the presence of native elastase, $\alpha_{1}$-proteinase inhibitor, or $\alpha_{2}$-macroglobulin

Native uncomplexed elastase causes no significant incorporation of $\left[{ }^{3} \mathrm{H}\right]$ glucose into hyaluronate (tab. 1). Only a moderate increase of ${ }^{35} \mathrm{SO}_{4}^{2-}$-incorporation into extracellular chondroitin sulphate was found when synovial fibroblasts were incubated with native elastase $(2.2,22.4 \mathrm{nmol} / \mathrm{l})$. In the presence of higher concentrations of native elastase $(224 \mathrm{nmol} / \mathrm{l})$ a trypsin-like effect was obșerved, evident by detachment of the monolayer cells. In samples taken during the incubation of the synovial fibroblasts with native elastase no elastase- $\alpha_{1}$-prọteinase inhibitor complexes were detectable by an enzyme immunoassay (detection limit: $10 \mathrm{pmol} / \mathrm{l})$, which indicates that no $\alpha_{1}$ proteinase inhibitor was released by the cells in culture.

Concentrations of $\alpha_{2}$-macroglobulin similar to those found in synovial fluids from patients with chronic joint diseases effect no changes on the glycosaminoglycan metabolism. Native $\alpha_{1}$-proteinase inhibitor, however, strongly inhibits the incorporation of $\left[{ }^{3} \mathrm{H}\right]$ glucosamine into hyaluronate $(90 \%$ inhibition of total hyaluronate synthesis) and of ${ }^{35} \mathrm{SO}_{4}^{2-}$ into chondroitin sulphate (97\% inhibition), derived from the different compartments of the cell culture (tab. 1).

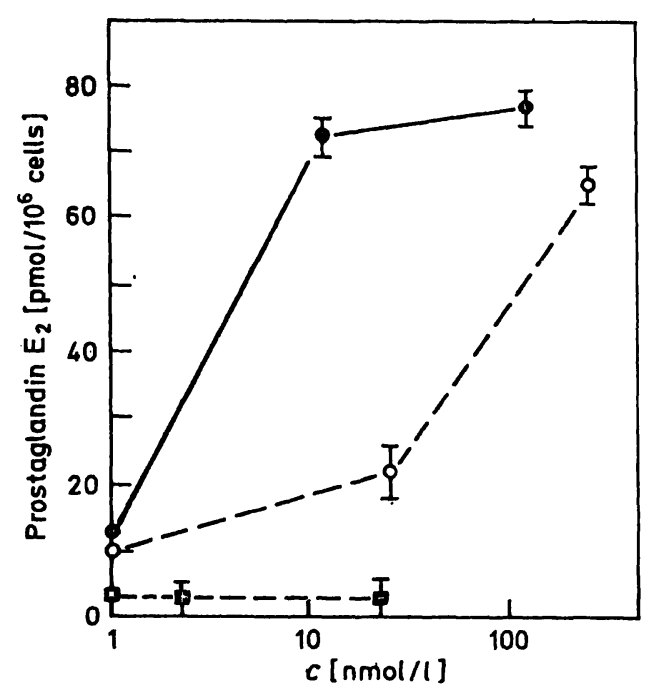

Fig. 4. Effect of granulocyte elastase ( $\square-\square)$, elastase- $\alpha_{2}$-macroglobulin complexes $(0-0)$, and elastase- $\alpha_{1}$-proteinase inhibitor complexes $(0-0)$ on the concentration of prostaglandin $E_{2}$ in the medium of synovial fibroblast cultures. Mean and standard deviation are given.

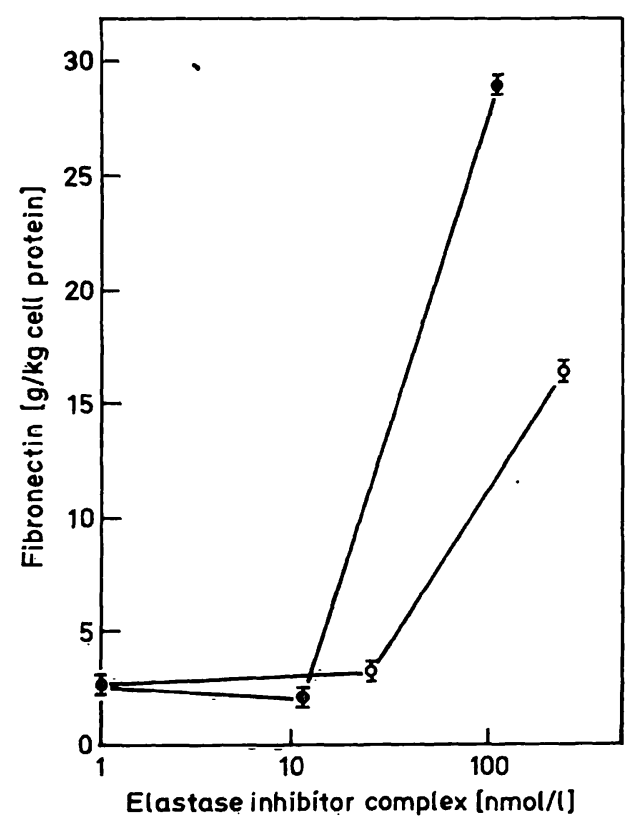

Fig. 5. Effect of elastase- $\alpha_{2}$-macroglobulin complexes (o-0) and elastase- $\alpha_{1}$-proteinase inhibitor complexes $(0-0)$ on the concentration of fibronectin in the medium of synovial fibroblast cultures. Mean and standard deviation are given.

\section{Discussion}

Previous investigations have shown that cells in culture, grown from the synovial membrane of the kneejoint, synthesize hyaluronate (as the predominant glycosaminoglycan) and proteochondroitin sulphate (19). Details of the intracellular synthesis of proteoglycans have been described previously for different experimental systems $(27,28)$. It has been suggested that the initiation of biosynthesis of chondroitin sul- 
phate chains occurs in the rough endoplasmic reticulum while the protein core is nascent $(29,30)$. It is assumed that the chondroitin sulphate chains are subsequently assembled mainly in the smooth endoplasmic reticulum-Golgi complex (31).

Cultured synovial fibroblasts have been shown to distribute newly synthesized radiolabelled glyçosaminoglycans in different compartments of the cell culture $(32,33)$. A considerable amount of the radioactive material is secreted into the culture medium (extracellular compartment). Glycosaminoglycans of distinct composition remain in association with the cell membrane (pericellular compartment) and can be solubilized by trypsin. Another fraction of the synthesized macromolecules remains inside the cell (intracellular compartment), and is either transferred into the lysosomes for immediate degradation or internalized, e.g. by the nucleus and mitochondria $(34,35)$. The simultaneous investigation of the intra-, peri-, and extracellular glycosaminoglycans allows further insight into partial steps of metabolism, such as intracellular synthesis, secretion into the extracellular medium, reuptake of macromolecules, and intracellular degradation.

In our study, during the incubation of cultured synovial fibroblasts with elastase-inhibitor complexes, we observed not only an enhancement of total glycosaminoglycans in the cell culture, but also a displacement of hyaluronate and chondroitin sulphate between the three compartments of the cell culture; an increase of glycosaminoglycans in the extracellular pool (medium) was accompanied by a corresponding decrease inside the cells and the pericellular space. This indicates that elastase-proteinase inhibitor com: plexes stimulate both the synthesis and secretion of hyaluronate and chondroitin sulphate. No significant changes of hyaluronate metabolism and only a slight increase of the radiolabelled chondroitin sulphate were found after incubation of the synovial cells with native elastase.

The cultured synovial cells used in our experiments cannot be differentiated by light microscopy, but were possibly composed of fibroblast-like and macrophage-like cell types, which have been shown to be present in the synovial membrane by electron microscopy (36). It has been shown that proteinase$\alpha_{2}$-macroglobulin complexes are endocytosed by both tissue macrophages and fibroblasts $(37-40)$. In previous publications it was reported that large amounts of $\alpha_{2}$-macroglobulin could be detected intracellularly in normal human fibroblasts cultured in medium supplemented with serum (41). $\alpha_{2}$-Macroglobulin was shown to be taken up from the miedium by the fibro- 
blasts at a remarkably high rate. Kinetic analysis of this uptake mechanism suggests that exclusively complexes of $\alpha_{2}$-macroglobulin with proteinases were taken up by the cells (42). Previous results therefore provide strong evidence for the presence of a proteinase- $\alpha_{2}$-macroglobulin receptor on the cell surface of fibroblasts (39).

Binding of proteinases to $\alpha_{2}$-macroglobulin leads to a drastic conformational change in the $\alpha_{2}$-macroglobulin resulting in physical entrapment of the proteinase. The calcium-dependent specific recognition by a cell surface receptor of $\alpha_{2}$-macroglobulin-proteinase complexes, and not of the native molecule, is most likely due to this conformational reorganization of the $\alpha_{2}$-macroglobulin molecule upon complexation $(40,43)$. The entrapment of the proteinase by $\alpha_{2}$ macroglobulin suggests that it is the $\alpha_{2}$-macroglobulin part of the complex which is recognized by the receptor and not the proteinase. This point is substantiated by the use of different $\alpha_{2}$-macroglobulin-proteinase complexes, i.e. trypsin- $\alpha_{2}$-macroglobulin and collagenase- $\alpha_{2}$-macroglobulin complexes, which behaved quite similarly in uptake studies $(42,44)$.

Tissue macrophages likewise have surface receptors that make the uptake and clearance of $\alpha_{2}$-macroglobulin-bound proteinases from the extracellular space possible $(38,40,45)$. This receptor system also only operates when $\alpha_{2}$-macroglobulin is complexed with proteinases.

Proteinase- $\alpha_{2}$-macroglobulin complexes released into the circulation are believed to be removed rapidly by reticuloendothelial cells (46). Recent in vitro studies with rats have shown that the uptake of trypsin- $\alpha_{2}-$ macroglobulin complex into hepatocytes $(85-90 \%)$ and Kupffer cells (4-9\%) appears to account for the major part of its uptake by the liver and thereby for its rapid removal from the blood (47). In the joint cavity, however, which is not in direct contact with the blood circulation, the proteinase-inhibitor complexes accumulate. During inflammatory processes the local release of proteinases from phagocytes, associated with an enhanced diffusion of plasma $\alpha_{2}-$ macroglobulin through the blood-synovial fluid barrier, leads to an interaction of proteinase- $\alpha_{2}$-macroglobulin complexes with the surrounding connective tissue cells of the synovial system.

The uptake of proteinase- $\alpha_{2}$-macroglobulin complexes by tissue macrophages and fibroblasts of the synovial system initiates a number of biochemical events, including an enhanced release of prostaglandins, which are detectable in high concentrations in inflammatory synovial fluids (48).
Macrophages which respond to phlogogenic stimuli release large amounts of arachidonic acid oxygenation products and seem to be the main source of prostaglandins in inflammatory joints. Previous studies have shown that the challenge of quiescent mouse peritoneal macrophages with zymosan particles leads to a burst-like production of prostaglandin $E_{2}$ and prostaglandin $I_{2}(49)$. Endogenous arachidonic acid present in the membrane phospholipids serves as substrate. During culturing of phagocytosis-stimulated macrophages prostaglandins are produced in large quantities at the initial phase of the stimulation, and the release of prostaglandin into the culture medium appears to cease completely within two days after activation (50). Resting macrophages produce only small amounts of prostaglandins.

It has been reported that macrophage-like cells, which normally make up one third of the lining cells (51), and are resident macrophages of the synovial membrane, are part of the organism's mononuclear phagocyte system and show many typical biochemical functions common to tissue macrophages of different provenance. Endocytosis of substances by those macrophages might be accompanied by the production of prostaglandins $(52,53)$.

Exposure of the synovial cells to elastase-inhibitor complexes leads to an increase of prostaglandin $E_{2}$ in the culture medium, most pronounced in the presence of elastase- $\alpha_{2}$-macroglobulin complexes, whereas native elastase does not show a significant effect. Assuming that the cells in culture consist of fibroblast-like and macrophage-like cells, it is not known whether the cells secreting prostaglandin $E_{2}$ are identical with those that are able to synthesize hyaluronate.

It has been suggested that the endocytotic process in general, independent of the type of cells, leads to an increased formation of prostaglandins (52). The intracellular vacuolisation during endocytosis seems to correlate and coincide with prostaglandin formation and might be due to the internalization of membranes containing arachidonic acid-rich phospholipids, as well as to the fusion of different cell organelles, thus providing more substrate for the generation of prostaglandins. The increase of prostaglandin $E_{2}$ in the synovial fibroblast culture medium during incubation with elastase- $\alpha_{2}$-macroglobulin complexes, which was observed in our study, is probably the consequence of endocytosis of these complexes by the cells in culture.

The cultured synovial cells produce prostaglandins and are also at the same time subject to regulation by prostaglandins. In vitro studies have shown that 
the external addition of prostaglandins to macrophages inhibits the metabolic capacity to generate oxygen-derived radicals and also the phagocytic and pinocytic functions (54). Furthermore, all data indicate that in particular prostaglandin $E_{2}$ increases glycosaminoglycan synthesis in fibroblasts, both in vivo and in vitro. The actions of the prostaglandins are probably mediated through increased intracellular levels of cyclic nucleotides $(53,55)$. Furthermore, it has been reported that inhibitors of prostaglandin synthesis also cause a decrease of hyaluronate synthesis in synovial fibroblasts (19). Thus, from our studies with cultured synovial cells, it might be concluded that the increased synthesis of hyaluronate and chondroitin sulphate in the presence of elastase inhibitor complexes is primarily caused by an enhanced release of prostaglandin.

It seems that there is no uptake of elastase- $\alpha_{1}$-proteinase inhibitor complexes in macrophages comparable to that which occurs with $\alpha_{2}$-macroglobulin complexes $(45,56)$. In vitro studies with rabbit alveolar macrophages have shown a rapid uptake of proteinase- $\alpha_{1} / \alpha_{2}$-macroglobulin complexes by the cells, but it has been reported that complexes of labelled trypsin or subtilopeptidase A with rabbit $\alpha_{1}$-proteinase inhibitor do not become similarly associated with the cell surface and were not endocytosed. It was also observed that proteinase- $\alpha_{1}$-proteinase inhibitor complexes fail to inhibit the uptake of proteinase- $\alpha_{2}-$ macroglobulin complexes (56). Thus, $\alpha_{1}$-proteinase inhibitor and $\alpha_{2}$-macroglobulin-binding provide separate mechanisms for disposal of proteinases.

Little is known about the uptake of proteinase- $\alpha_{1}$ proteinase inhibitor complexes, especially of elastase$\alpha_{1}$-proteinase inhibitor complexes, by fibroblasts. Whether the enhanced release of prostaglandin and the increased synthesis and secretion of hyaluronate in the presence of elastase- $\alpha_{1}$-proteinase inhibitor complexes, found in our studies with cultured synovial cells, is mediated by an endocytotic process is therefore not yet clear and needs further investigation. There is also no information concerning the uptake of native uncomplexed elastase by fibroblasts. It has been reported that macrophages and granulocytes specifically bind and ingest unbound elastase $(45,57,58)$. A receptor-mediated endocytosis of elastase by synovial cells, however, seems to be unlikely, since our investigations have shown that the uncomplexed proteinase failed to stimulate glycosaminoglycan and prostaglandin metabolism.

When we studied the influence of the native proteinase inhibitors alone, no significant effect of $\alpha_{2}$-macro- globulin on hyaluronate and chondroitin sulphate metabolism was detectable. Physiological concentrations of $\alpha_{1}$-proteinase inhibitor, however, showed a strong inhibitory effect on glycosaminoglycan metabolism, particularly with respect to the synthesis of hyaluronate and its secretion into the extracellular compartment. The mechanism of inhibition by $\alpha_{1-}$ proteinase inhibitor is not well understood, and is probably due to the reaction of the proteinase inhibitor with cell membrane-associated proteinases. Membrane-associated proteinases have been claimed by several investigators in lymphocytes, granulocytes, kidney tissue, macrophages (59) and human fibroblasts (60). Proteinases, which exhibit the properties of elastase, have been isolated from purified cell membranes of human monocytes and lymphocytes (61). It has also been postulated that such membranebound proteinases may play a dominant role in macrophage-mediated degradation of connective tissue (62). It has been shown that $\alpha_{1}$-proteinase inhibitor decreases the mixed lymphocyte response (63), the activity of killer cells and antibody-dependent cellmediated cytotoxicity (64).

The extracellular reaction of elastase with proteinase inhibitors leads to an almost complete loss of proteolytic activity, but it does not result in the formation of metabolically inactive protein complexes. Our studies with synovial cell cultures rather indicate that potent inflammatory mediators are generated, which seem to be involved basically in inflammatory joint processes. Elastase-inhibitor complexes stimulate synovial cell cultures to show a constellation of findings closely resembling the metabolic activities present in inflammatory synovial systems, including accelerated synthesis and secretion of hyaluronic acid, increased formation of prostaglandins, as well as an enhanced glucose consumption and lactic acid production. We have further shown that exposure of synovial fibroblast cultures to elastase-inhibitor complexes induces a rise in the fibronectin concentration in the medium. This finding is also in good agreement with the in vivo data during an inflammatory joint disease, in which elevated fibronectin levels were observed in the synovial fluid but not in the blood plasma $(65,66)$.

\section{Acknowledgements}

We are grateful to Dr. H. Lang and Dr. S. Neumann, Biochemical Research, Merck, Darmstadt, for providing human elastase and proteinase inhibitors.

This study was supported by grants from the Deutsche Forschungsgemeinschaft (Kl 388/4-1). 


\section{References}

1. Barrett, A.J. (1978) Agents Actions 8, 11-18.

2. Lowther, D.A., Sandy, J.D., Santer, V.B. \& Brown, H. L. G. (1978) Arthritis Rheum. 21, 675-680.

3. Velvart, M., Fehr, K., Baici, A., Sommermeyer, G., Knopfel, M., Cancer L. M., Salgam, P. \& Böni, A. (1981) Rheumatol. Int. $1,121-130$.

4. Bartholomew, J. S., Lowther, D. A. \& Handley, C. J. (1984) Arthritis Rheum. 27, 905-912.

5. Weissmann, G., Zurier, R. B. \& Hoffstein, S. (1972) Am. J. Pathol. 68, 539-559.

6. Goldstein, I. R. A., Hoffstein, S., Gallin, J. \& Weissmann, G. (1973) Proc. Natl. Acad. Sci. USA 70, 2916-2920.

7. Klempner, M.S., Dinarello, C. A. \& Gallin, J.I. (1978) J. Clin. Invest. 61, 1330-1336.

8. Weissmann, G. \& Rita, G. A. (1972) Nature New Biol. 240, $167-172$.

9. Starkey, P. M. (1980) In: Frontiers of Matrix Biology (Robert, A. M. \& Robert, L. eds.) Karger, Basel, Vol. 18, pp. $188-198$.

10. Ohlsson, K. \& Olsson, I. (1974) J. Clin. Lab. Invest. 34, $349-355$.

11. Bieth, J. G. (1980) In: Frontiers of Matrix Biology (Robert, A. M. \& Robert, L. eds.) Karger, Basel, Vol. 18, pp. $216-227$.

12. Twumasi, D. Y., Liener, I. E., Galdston, M. \& Lezytska; V. (1977) Nature 267, 61-63.

13. Ohlsson, K. \& Laurell, C. B. (1976) Clin. Sci. Mol. Med. $51,87-92$.

14. Vischer, T. L. \& Berger, D. (1980) J. Reticuloendothel. Soc. 28 (Suppl.), 427-435.

15. Kleesiek, K. \& Greiling, H. (1984) Int. J. Microcirc. Clin. Exp. 3, 131-145.

16. Kleesiek, K., Neumann, S. \& Greiling, H. (1982) Fresenius Z. Anal. Chem. 311, 434-435.

17. Adeyemi, E.O., Hull, R.G., Chadwick, V.S., Hughes, G.R.V. \& Hodgson, H.J.F. (1986) Rheumatol. Int. 6, $57-60$.

18. Kleesiek, K., Reinards, R., Brackertz, D., Neumann, S., Lang, H. \& Greiling, H. (1986) Rheumatol. Int. 6, $161-169$

19. Kleesiek, K. \& Greiling, H. (1982) Rheumatol. Int. 2, $167-174$

20. Greiling, H., Stuhlsatz,.H.W., Eberhard, T. \& Eberhard, A. (1975) Connect. Tissue Res. 3, 135-139.

21. Saito, H., Yamagata, T. \& Suzuki, S. (1968) J. Biol. Chem. 243, 1536-1542.

22. Neumann, S., Gunzer, G., Hennrich, N. \& Lang, H. (1984) J. Clin. Chem. Clin. Biochem. 22, 693-697.

23. Lowry, O.H., Rosebrough, N.J., Farr, A. L. \& Randall, R. J. (1951) J. Biol. Chem. 193, 265-275.

24. Kunst, A., Draeger, B. \& Ziegenhorn, J. (1984) In: Methods of Enzymatic Analysis (Bergmeyer, H. U., ed.) Verlag Chemie, Weinheim, Vol. VI, pp. $163-172$.

25. Noll, F. (1984) In: Methods of Enzymatic Analysis (Bergmeyer, H.U., ed.) Verlag Chemie, Weinheim, Vol. VI, pp. $582-588$.

26. Sachs, L. (1984) Angewandte Statistik: Anwendung statistischer Methoden, 6. Auflage, Springer Verlag, Berlin.

27. Rodén, L. \& Schwartz, N. B. (1975) Int. Rev. Sci. (Ser I) $5,96-152$

28. Muir, I.H.M. (1980) In: The joints and synovial fluid (Sokoloff, L., ed.) Academic Press, New York, London, pp. 27-94.

29. Horwitz, A.L. \& Dorfman, A. (1968) J. Cell Biol. 38, $358-368$
30. Schwartz, N. B., Geetha-Habib, M., Campbell, S., d'Elvlyn, D., Gartner, M., Krueger, R., Olson, C. \& Philipson, L. (1985) Fed. Proc. 44, 369-372.

31. Silbert, J.E. \& Freilich, L.S. (1980) Biochem. J. 190, $307-313$.

32. Neufeld, E.F. \& Cantz, M. (1973) In: Lysosomes and storage diseases (Hers, H. G. \& van Hoof, F., eds.) Academic Press, New York, pp. 261-275.

33. Kresse, H., Figura, K. von, Buddecke, E. \& Fromme, H. G. (1975) Hoppe-Seyler's Z. Physiol. Chem. 356, 929-941.

34. Fromme, H. G., Buddecke, E., Figura, K. von \& Kresse, H. (1976) Exp. Cell Res. 102, 445-449.

35. Dietrich, C.P., Sampaio, L. O. \& Toledo, O. M. S. (1976) Biochem. Biophys. Res. Comm. 71, 1-10.

36. Barland, P., Novikoff, A. B. \& Hamerman, D. (1962) J. Cell Biol. 14, 207-212.

37. Mosher, D. F. \& Vaheri, A. (1980) Biochim. Biophys. Acta $627,113-122$.

38. Kaplan, J. \& Nielsen, M. L. (1979) J. Biol. Chem. 254, $7329-7335$.

39. Van Leuven, F., Cassiman, J.-J. \& Van Den Berghe, H. (1979) J. Biol. Chem. 254, 5155-5160.

40. Imber, M. J. \& Pizzo, S. V. (1981) J. Biol. Chem. 256, 8134-8139.

41. Van Leuven, F., Verbruggen, R., Cassiman, J.-J. \& Van Den Berghe, H. (1977) Exp. Cell Res. 109, 468-471.

42. Van Leuven, F., Cassiman, J.-J. \& Van Den Berghe, $H$. (1978) Exp. Cel! Res. 117, 273-282.

43. Starkey, P. M. \& Barrett, A. J. (1977) In: Proteinases in Mammalian Cells and Tissues (Barrett, A. J., ed.), Elsevier/ North-Holland, Amsterdam, pp. 663-696.

44. Feldman, S. R., Ney, K. A., Gonias, S. L. \& Pizzo, S. V. (1983) Biochem. Biophys. Res. Comm. 114, 757-762.

45. Campbell, E.J., White, R.R., Senior, R.M., Rodriquez, R. J. \& Kuhn, C. (1979) J. Clin. Invest. 64, 824-833.

46. Ohlsson, K. (1971) Acta Physiol. Scand. 81, 269-272.

47. Davidsen, O., Christensen, E. I., Gliemann, J. (1985) Biochim. Biophys. Acta 846, 85-92.

48. Trang, L. E., Granström, E. \& Lövgren, O. (1977) Scand. J. Rheumatol. 6, 151-154.

49. Humes, J.L., Bonney, R.J., Pelus, L., Dahlgren, M.E., Sadowski, S., Kuehl, F. A. \& Davies, P. (1977) Nature 269, 149-151.

50. Baggiolini, M., Schnyder, J., Dewald, B., Bretz, U. \& Payne, T. G. (1982) Immunobiology 161, 369-375.

51. Barland, P., Novikoff, A. B. \& Hamerman, D. (1964) Am. J. Pathol. 44, 853-866.

52. Brune, K., Glatt, M., Kälin, H. \& Peskar, B. A. (1978) Nature 274, $261-263$.

53. Birmelin, M. \& Decker, K. (1984) Eur. J. Biochem. 142 , $219-225$.

54. Oropeza-Rendon, R. L., Bauer, H. C. \& Fischer, H. (1980) J. Immunopharmacol. 2, 133-147.

55. Bonta, I. L. \& Parnham, M. J. (1978) Biochem. Pharmacol. 27, $1611-1623$

56. Dolovich, J., Debanne, M.T. \& Bell, R. (1975) Am. Rev. Resp. Dis. 112, 521-525.

57. Dwenger, A., Tost, P. \& Holle, W. (1986) J. Clin. Chem. Clin. Biochem. 24, 299-308.

58. Campbell, E.J. (1982) Proc. Natl. Acad. Sci. USA 79 , $6941-6945$

59. Wachsmuth, E. D. \& Stoye, J. P. (1977) J. Reticuloendothel. Soc. $22,469-483$.

60. Hatcher, V. B., Wertheim, M.S., Rhee, C. Y., Tsien, G. \& Burk, P. G. (1976) Biochim. Biophys. Acta 451, 499-510. 
61. Fuks, A., Zucker-Franklin, D. \& Franklin, E.C. (1983) Biochim. Biophys. Acta 755, 195-203.

62. Werb, Z., Bainton, D. F. \& Jones, P. A. (1980) J. Exp. Med. $152,1537-1553$.

63. Hubbard, W. J., Hess, A. D., Hsia, S. \& Amos, D. B. (1981) J. Immunol. 126, 292-299.
64. Ades, E. W., Hinson, A., Chapuis-Cellier, C. \& Arnaud, P. (1982) Scand. J. Immunol. 15, 109-113.

65. Scott, D.L., Farr, M., Crocksson, A.P. \& Walton, K.W. (1982) Clin. Sci. 62, 71-76.

66. Gressner, A. M. \& Wallraff, P. (1980) J. Clin. Chem. Clin. Biochem. 18, 797-805.

Prof. Dr. K̇. K̇leesiek

Herzzentrum Nordrhein-Westfalen

Institut für Laboratoriums-

und Transfusionsmedizin

Georgstr. 11

D-4970 Bad Oeynhausen 